\title{
The Research on the Regulation Mechanism of Garbage Classification and Recycling Based on the Analysis of Subject Game
}

\author{
Moqiao Pu1, Xi Yu \\ ${ }^{1}$ School of Civil Engineering and Architecture, Southwest University of Science and Technology, Mianyang, China \\ ${ }^{2}$ School of Urban and Environmental Sciences, Northwest University, Xi'an, China \\ Email: 100184495@qq.com
}

How to cite this paper: Pu, M.Q. and Yu, X. (2021) The Research on the Regulation Mechanism of Garbage Classification and Recycling Based on the Analysis of Subject Game. Open Access Library Journal, 8: e7536. https://doi.org/10.4236/oalib.1107536

Received: May 17, 2021

Accepted: June 18, 2021

Published: June 21, 2021

Copyright $\odot 2021$ by author(s) and Open Access Library Inc.

This work is licensed under the Creative Commons Attribution International License (CC BY 4.0).

http://creativecommons.org/licenses/by/4.0/ (c) (i) Open Access

\begin{abstract}
At present, the transformation of garbage collection and treatment has been carried out nationwide, so it is imperative to classify garbage collection. There are residents, private enterprises and government departments in the waste recycling process. This paper takes Xi'an city as an example, from the perspective of the participants of garbage classification and recycling, finds that there are "game" dilemmas and many practical problems in the implementation of classification and recycling. Through the analysis of the attitude and role of the "subject" game, a three-party evolutionary game model of garbage classification and recycling supervision is established, and the expected utility of the "subject" is calculated and simulated. Based on the calculation results, the possible behavior strategies of the "subject" are revealed. On the basis of the above, measures and suggestions are put forward to optimize and improve the management system of garbage classification and recycling.
\end{abstract}

\section{Subject Areas \\ Urban Development Research}

\section{Keywords}

Garbage Classification, Management Mechanism, Tripartite Evolutionary Game

\section{The Process of Garbage Sorting Is Slow}

\subsection{The Evolution of Domestic Waste Classification Policies}

With the progress of global urbanization, the problem of urban garbage siege has 
become increasingly serious. About one-third of the cities in my country are surrounded by garbage, and the accumulation of large amounts of garbage has caused serious harm to the environment and organisms [1]. Facing the severe situation, the United Nations Environment Programme in 2012 called for a sustainable development method to sort and recycle, sort treatment, turn waste into treasure, and solve the waste problem at the "Waste Management Global Partnership" meeting. The difficulty of my country's waste sorting, recycling and processing lies in the balance of self-interest under the multi-party game [2]. Only by balancing the interests of all parties and optimizing and improving the management system of waste sorting and recycling can the sorting and recycling be truly feasible.

Since my country's 18th National Congress of the Communist Party of China proposed the construction of characteristic ecological civilization, the issue of waste classification and recycling related to the construction of ecological civilization has attracted great attention [3]. Since my country's Ministry of Construction selected 8 major cities such as Beijing and Hangzhou for waste sorting and disposal in 2000, the problem of urban domestic waste has gradually attracted great attention from the society. In December 2016, the "Thirteenth Five-Year Plan" National Urban Domestic Waste is Harmless according to the requirements of the "Plan for the Construction of Chemical Treatment Facilities", the Chinese government has gradually begun to use administrative means to strengthen the awareness of waste classification (see Table 1). As a city facing the siege dilemma due to the excessive production of domestic waste for many years, Xi'an has never stopped exploring and promoting garbage classification, but various signs indicate that the progress of garbage classification is constantly cold. On April 16, 2019, the 86th of Xi'an Municipal People's Government, the second executive meeting deliberated and approved the "Measures for the Classification and Management of Domestic Waste in Xi'an City," and it is planned to be formally implemented on September 1 [4] [5]. How to implement the management methods, how to break the shackles of "difficult waste classification" in the country, and establish a reasonable and effective treatment path. The recycling mechanism has become the focus of attention of all parties. At present, the experience of domestic classification pilots inevitably faces the dilemma of "difficulty in classification and disposal" of community domestic garbage. There are the following types of problems in garbage classification: 1) The cognitive level and self-consciousness of each subject are not high. Some public relations agencies and related companies have a low level of awareness and awareness. The main responsibility is not strong, the measures are not effective, and the implementation of garbage classification is not ideal. In addition, some community residents are not clear about the garbage classification standards, or find it troublesome. Random and mixed disposal of domestic garbage is common, causing relevant departments and enterprises to have to implement "secondary classification" [6]. 2) The dilemma of high costs and low returns. The garbage sorting 
Table 1. Domestic documents related to garbage classification released.

\begin{tabular}{|c|c|c|c|}
\hline Time & $\begin{array}{l}\text { Publishing } \\
\text { department }\end{array}$ & File name & Main content \\
\hline $\begin{array}{l}\text { September } \\
2015\end{array}$ & $\begin{array}{l}\text { Central } \\
\text { Committee of } \\
\text { the Communist } \\
\text { Party of China, } \\
\text { State Council }\end{array}$ & $\begin{array}{l}\text { "Overall Plan for } \\
\text { Reform and Reform } \\
\text { of Ecological } \\
\text { Civilization System" }\end{array}$ & $\begin{array}{l}\text { Speed up the establishment of a } \\
\text { mandatory garbage classification } \\
\text { system, and implement mandatory } \\
\text { recycling of low-value waste such as } \\
\text { composite packaging, batteries, and } \\
\text { agricultural films. }\end{array}$ \\
\hline $\begin{array}{l}\text { December } \\
2016\end{array}$ & $\begin{array}{l}\text { National } \\
\text { Development } \\
\text { and Reform } \\
\text { Commission, } \\
\text { Ministry of } \\
\text { Housing and } \\
\text { Urban-Rural } \\
\text { Development }\end{array}$ & $\begin{array}{l}\text { "Thirteenth } \\
\text { Five-Year Plan } \\
\text { National Urban } \\
\text { Domestic Waste } \\
\text { Harmless } \\
\text { Treatment Facilities } \\
\text { Construction Plan" }\end{array}$ & $\begin{array}{l}\text { To speed up the construction of } \\
\text { treatment facilities, it is necessary to } \\
\text { improve the garbage collection and } \\
\text { transportation system, including the } \\
\text { overall arrangement of domestic } \\
\text { garbage transfer stations, eliminate } \\
\text { open collection and transportation } \\
\text { facilities, and strengthen the } \\
\text { upgrading and transformation } \\
\text { of garbage operation stations. }\end{array}$ \\
\hline March 2017 & $\begin{array}{l}\text { National } \\
\text { Development } \\
\text { and Reform } \\
\text { Commission, } \\
\text { Ministry of } \\
\text { Housing and } \\
\text { Urban-Rural } \\
\text { Development }\end{array}$ & $\begin{array}{l}\text { "Implementation } \\
\text { Plan of Domestic } \\
\text { Waste Classification } \\
\text { System" }\end{array}$ & $\begin{array}{l}\text { It is required to test first in } 46 \text { pilot } \\
\text { cities, compulsory classification of } \\
\text { domestic waste, and establish a } \\
\text { system of laws, regulations and } \\
\text { standards for waste classification } \\
\text { before the end of } 2020 \text {. }\end{array}$ \\
\hline July 2018 & $\begin{array}{l}\text { National } \\
\text { Development } \\
\text { and Reform } \\
\text { Commission }\end{array}$ & $\begin{array}{l}\text { "Opinions on } \\
\text { Innovating and } \\
\text { Improving the } \\
\text { Price Mechanism } \\
\text { for Promoting } \\
\text { Green } \\
\text { Development" }\end{array}$ & $\begin{array}{l}\text { Comprehensively establish a } \\
\text { reasonable cost and profitable } \\
\text { solid waste treatment charging } \\
\text { mechanism, and accelerate the } \\
\text { establishment of an incentive and } \\
\text { restraint mechanism that is } \\
\text { conducive to promoting waste } \\
\text { classification and reduction, } \\
\text { resource utilization, and } \\
\text { harmless treatment. }\end{array}$ \\
\hline June 2019 & $\begin{array}{l}\text { Nine ministries } \\
\text { including the } \\
\text { Ministry of } \\
\text { Housing and } \\
\text { Urban-Rural } \\
\text { Development }\end{array}$ & $\begin{array}{l}\text { "Notice on the } \\
\text { comprehensive } \\
\text { implementation } \\
\text { of domestic waste } \\
\text { classification in } \\
\text { cities at } \\
\text { prefecture-level } \\
\text { and above across } \\
\text { the country" }\end{array}$ & $\begin{array}{l}\text { By } 2020,46 \text { key cities will have } \\
\text { basically completed domestic waste } \\
\text { sorting and processing systems. }\end{array}$ \\
\hline
\end{tabular}

and processing links are scattered in different levels of administrative management departments, and administrative costs, economic costs, and social costs are significantly higher than those of non-sorting. At the same time, the unreasonable garbage charging system and management system, and low-value-added 
waste sorting and resource-based products are also Will affect the enthusiasm of neighborhood communities and garbage disposal companies. 3) Insufficient policy design and coordinated promotion. Garbage collection and transportation and classification treatment are managed and implemented by different departments, and the coordination and coordination are not enough. Passive and extensive mixed collection and centralized transportation and treatment methods are far from the system goals of classified delivery, classified collection, classified transportation, and classified treatment stipulated by the state [7]. Therefore, the garbage classification management system and operating mechanism need to be reformed urgently.

Urban environmental sanitation is a typical public item. In addition to public services provided by the government, there are other types of participation and influence in the classification and treatment of urban waste. The difficulty of waste classification is the difficulty of the urban environmental sanitation management mechanism, and the path to solve the problem While realizing the fairness of individuals and groups, it implements a garbage classification system that conforms to individual and social rationality, and achieves the Nash equilibrium in the game of each participant in the classification process. Through a comprehensive survey of the types, processes and destinations of domestic waste, this paper clarifies the three types of participants: residents, private recyclers and the government, and conducts in-depth analysis from the perspectives of residents, recyclers and the government. The game model evolves, exploring the effective mechanism of waste classification and recycling, and conducts empirical research with Xi'an as the research object, hoping to provide theoretical support for the effective advancement of my country's waste classification practice.

\subsection{The Evolution of Waste Disposal Methods in Recent Years}

This article takes community domestic waste as the object, and explores the deep-level mechanism of waste classification through the investigation and analysis of existing domestic waste types, processes, current treatment standards, as well as residents, recyclers and relevant government personnel. Based on the analysis of relevant data from the Xi' an City Appearance and Landscape Bureau, the 24 residential areas within the ring expressway with a large amount of garbage and high transportation frequency were selected as the main areas for the survey [8]. A total of 282 questionnaires were issued to residents, and 269 valid questionnaires were obtained. Interviews with environmental experts, government staff of the City Appearance and Landscape Bureau, Environmental Protection Bureau and other departments, as well as staff involved in waste sorting, recycling, transportation, treatment, and related enterprises, and conduct detailed investigation and analysis of the behavior of each subject in the waste sorting process, and construct The applicable game model aims to verify the applicability of the current classification standards, and on the basis of it, propose relevant solutions to the mechanism problems reflected in the status quo of re- 
cycling, in order to provide relevant social, economic and social, economic and Environmental benefits [9].

Take Xi'an as an example. Before the management measures were issued, the garbage classification methods were mainly recyclable and non-recyclable garbage. The waste end treatment method is mainly sanitary landfill, which accounts for more than $98 \%$ of the total waste, and the remaining less than $2 \%$ of the waste is treated in a comprehensive way, using composting, incineration and adding fermented enzymes to make fertilizer (SWR technology (Yanliang District Domestic Waste Resource Treatment Plant) and other methods for processing [8]. As of May 2010, a total of 8 domestic waste treatment facilities have been built in Xi'an, including harmless landfills constructed in accordance with the national standards "Technical Specifications for Domestic Waste Landfill" and "Hazardous Evaluation Standards for Domestic Waste Landfill Sites" In addition to the Grade I landfill, the other two were Gaoling County Landfill and were completed and put into use in January 2009 [9]. The Lintong District Domestic Waste Landfill will be completed and put into use in June 2010, Lantian, Zhouzhi and Huxian use simple domestic waste landfills [10]. The Jiangcungou Landfill in Bailuyuan, eastern suburbs of Xi'an, accepts about 10,000 tons of waste every day [11]. By October 19, the Jiangcungou Landfill will have no space to fill and will be closed. From September 1, 19, Xi'an began to implement waste classification management regulations. Among the 3600 communities in Xi'an, more than 600 communities have been piloting waste sorting so far. It is required that by the end of 19 , the coverage of classified communities should reach $50 \%$ [12]. The urgent capacity of landfill sites and the huge waste of urban resources have made it necessary for Xi'an to quickly identify the crux of the classification dilemma and propose effective standards and mechanisms for waste classification.

Garbage classification is based on the composition, use value and environmental impact of urban domestic garbage, and according to different treatment methods, the act of implementing classified disposal, classified collection, classified transportation and classified treatment. The goal is to achieve waste reduction, resource utilization, and harmlessness. How to maximize the recycling of waste with residual value is the core link of classification. Since the implementation of Xi'an's detailed waste classification method, communities and public places have responded positively, but the differences in the expression of facilities and classification methods have caused difficulties in classification recognition, and the key steps of classification cannot be completed.

\section{Difficulties in the Mechanism of Garbage Collection and Classification}

\subsection{Difficulties in Processing Flow}

2.1.1. The Types Are Complex and the Number Is Increasing Day by Day With the passage of time, the types of garbage have become more and more 
complex: from simple garbage such as coal ash and kitchen waste in the 70s to plastic bags in the 80s and 90s, and complex garbage such as leftovers, to old clothes and electronic waste., Expired cosmetics, product packaging and other diversified garbage. The survey found that the living room, kitchen and bathroom are the places where people generate more waste in their daily life units. Household trash bins are generally divided into three types: living room, kitchen and bathroom trash bins. Among them, kitchen waste bins produce $38 \%$ of the total garbage. \%, the living room and bathroom produce $34 \%$ and $27.5 \%$ respectively. According to the classification standards of domestic waste stipulated in the current management measures, it is divided into four categories: recyclables, kitchen waste, hazardous waste and other wastes. Compared with the simple spatial distribution results of the current household trash bins, two In this model, the types of garbage are mixed and mixed. If a large number of mixed domestic garbage is to be classified according to the standard, the residents need to invest energy in learning the standard on the one hand, and on the other hand, new classification facilities need to be placed in the household classification. The mixed input of garbage in household trash bins is an important factor that causes residents to be unable to sort in the community.

\subsubsection{Dealing with Undivided Streams}

Before the implementation of the classified management regulations, taking Xi'an as an example, $90 \%$ of the communities within the ring expressway have set up recyclable and non recyclable garbage cans. The community garbage flows through the three nodes of waste recycling station, compression station and landfill, and residents and scavengers directly participate in the flow process. Not only is there a mixed phenomenon of garbage cans in families and communities, but the garbage in communities is still transported in the form of "one bucket" and compressed and sent directly to the landfill. The garbage that should have been "separated" appears in the whole process without being treated differently. After the promulgation of the management and implementation measures, most communities have set up recycling facilities according to the classification standards, but under the existing conditions of garbage transportation, part of the garbage can not be transported to the corresponding treatment terminal in the classified state, and the non diversion of treatment is another main factor that the garbage in the community can not be completely classified.

\subsubsection{There Is a Backflow Phenomenon}

From the current garbage disposal process, it is found that there is no special way for recyclable materials to enter the waste recycling station, but only rely on the sorting of scavengers and the sale of waste products by residents. Because the source did not separate the recyclable materials separately, in addition to the garbage collected by the residents and scavengers sold to the recycling station, $21.7 \%$ of the garbage was transferred from the compression station to the landfill. A "backflow" phenomenon that is sorted again and resold to the recycle bin. 
In Xi'an there were 2.907 million tons in one year, $89 \%$ of the garbage was landfilled, and only 32.9 tons of garbage was recycled again, of which 63.09 tons of landfilled garbage, $21.7 \%$ of the landfilled garbage was "refluxed".

\subsubsection{Overwhelmed Landfill}

Except for $11 \%$ of the daily garbage that can be recycled is sent to the recycling station, the rest is sent to the landfill, which puts great pressure on the landfill and the surrounding environment. The Jianggou Village Waste Landfill, which is about to be closed, is the only existing domestic waste treatment plant in Xi'an. The daily waste treatment capacity of the landfill was 2000 tons/day at the beginning of its completion in 1994, and the daily waste treatment capacity by 2014 Reaching 7000 tons/day, the average daily processing capacity is 3.5 times that of the initial design period, and the capacity is saturated in advance, making its service life about 20 years shorter than expected. Waste reduction in Xi'an is imminent. At the same time, due to the chaotic treatment process, there are currently some hazardous wastes, non-degradable plastics, expired drugs, etc. directly landfilled, causing great pollution to the agricultural land and living environment near the landfill, so the existing waste should not only be sourced Carry out classification, and put forward higher requirements for the improvement of terminal harmless treatment technology and the construction of facilities.

\subsection{Difficulties of Participants}

\subsubsection{Residents}

1) Classification habits

Five communities were randomly selected in the survey, and each community was equipped with classified trash bins corresponding to the management method, and two of them were still equipped with unsorted trash bins. After observing the behavior of residents throwing garbage in the community within 1 hour, it was found that 46 people throwing garbage within 1 hour. Everyone in the community where there are only sorted trash bins has been sorted out, but in the community with unsorted trash bins Only 2 people carried out classified placement. It can be seen that the residents' habit of classified placement has not been formed.

2) Classification attitude

According to the questionnaire survey data, most people think that it is necessary to classify garbage (see Figure 1), but in fact only a few people have fully grasped the standards for classifying garbage in the management method and strictly implement them in daily life (see Figure 2). It can be found that residents show the inconsistency of knowledge and behavior in garbage classification.

3) Factors hindering classification

According to the survey, most residents have not formed good garbage classification habits. At the same time, affected by their own inert psychology and lack of classification-related knowledge, they cannot correctly classify garbage. 56\% 


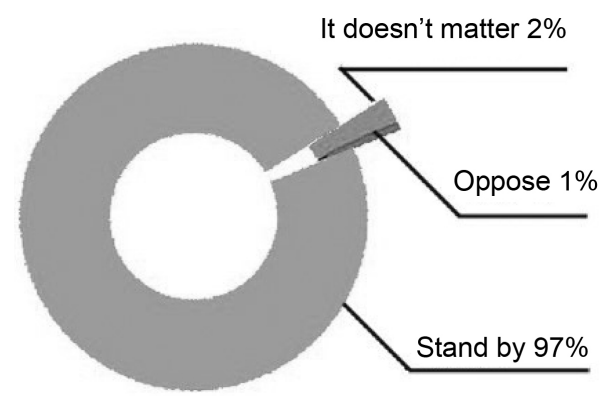

Figure 1. Resident classification attitude.

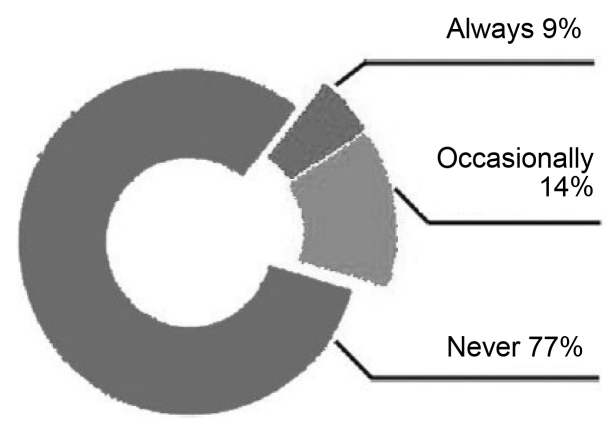

Figure 2. Resident classification behavior.

of residents say that they do not. Understand the relevant knowledge of garbage classification (see Figure 3), so children are rarely educated in daily life (see Figure 4). $90 \%$ of residents think that it is troublesome to re-sort the messy garbage, and they are unwilling to sort it. Another $60 \%$ of residents think that everyone is littering, and they will not abide by the relevant regulations. Multiple factors such as lack of classification knowledge, inertness, and herd mentality have become obstacles for residents to classify garbage, and have also aggravated the difficulty of garbage classification.

More residents blamed the imperfect classification facilities and imperfect classification system for the reasons why the classification could not be implemented. For example, the recycling facilities have mixed concept labels for various standards, and the illustrations have their own points, which makes it difficult for residents to throw garbage, so they turn a blind eye to the facility labels. Secondly, after the government has issued rigid standards, it is only for the facilities of some demonstration communities. Make standard settings. In the survey, $90 \%$ of residents indicated that they would be more than willing to classify them by themselves after the facilities are complete (see Figure 5). Through the above analysis, we can find that the classification behavior of residents is affected by themselves and objective factors.

\subsubsection{Private Recyclers}

Taking Xi'an as an example, there are three types of recycling entities in the private recyclers group: scavengers, waste recycling stations, and waste processing companies. Taking community private waste recycling (enterprise) as a direct 


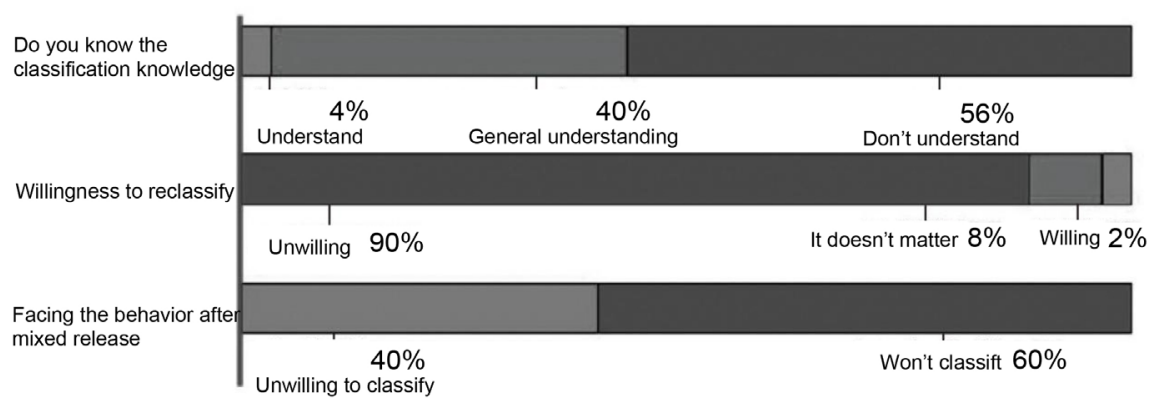

Figure 3. Residents' attitude and willingness to implement waste classification.

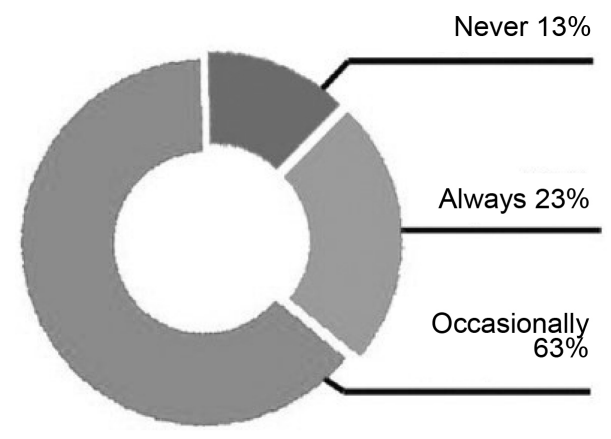

Figure 4. Education for children about garbage classification.

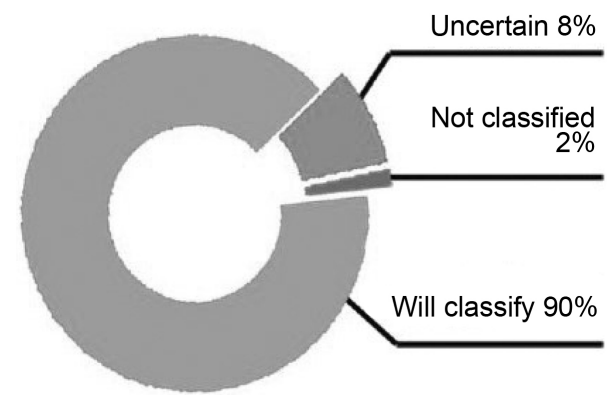

Figure 5. Residents' willingness to classify after the facilities is improved.

participant in community waste recycling is the main body of private recyclers in this study. There are three main ways to recycle existing waste recycling stations: community convenience recycling stations, private recycling stations and mobile recycling stations. Except for the community convenience recycling stations, which are directly managed by the state supply and marketing agency and provide subsidies, the latter two are private recycling stations. In the recycling process, there are two types of recycling methods: private and mobile, which are dense, concealed, and highly mobile. Participants are mostly involved, mostly through waste scavengers and some elderly residents in the community for batch garbage collection, but because of the lack of formal management, the irregular recycling behavior has some negative social impacts. There are currently 50 waste processing and manufacturing enterprises in Xi'an. However, due to the 
sluggish state of the renewable resource market and the limitations of recycling technology, carton and plastic processing enterprises are the main ones, which also has a certain impact on the overall waste classification process.

1) Interest relationship between recyclers

The relationship between scavengers, recycling stations, and enterprises is closely linked, and the chain of interests between them determines the type and quantity of garbage collection. Scavengers, recycling stations, and enterprises all recycle waste products based on the principle of "profiting big gains, profiting small ones, and no gains but not collecting", and the types of recycled waste will be affected by the higher-level entities, and the specific performance is more obvious. The survey results show that among the five types of recyclable garbage, only three types of recyclable waste are selected for recycling: waste plastic, waste paper, and waste metal.

2) Classification attitude of recycling entities

Through investigations, it is learned that recyclers have shown a dual attitude towards the issue of garbage classification. On the one hand, they want to increase the source of waste through garbage classification and bring considerable income; on the other hand, they will also worry that under the unified management of the government, after the integration of garbage classification and processing, if the government does not take some safeguard measures, So that the entire recycling industry will face the problem of unemployment.

\subsubsection{Government}

Taking Xi'an as an example, the disposal of domestic waste is mainly managed by the City Appearance and Landscape Bureau. The investigation revealed that before the introduction of the management measures, compared with other cities of the same level, Xi'an only proposed to speed up legislation and encourage classification in the classification and recycling of domestic waste. Since the introduction of the management measures, although there are standards in related fields, But it is inevitable that there are problems of incompleteness and incomplete system.

Regarding the current state of garbage sorting, the relevant staff said that their helplessness lies in: First, after sorting the garbage, tens of thousands of scavengers will face the problem of unemployment; second, limited resources, on the one hand, refined hardware processing Facilities will cost a lot of money. On the other hand, the supervision and implementation of classification requires a lot of manpower and material resources. As far as the current development status is concerned, it is difficult for the government to cover everything.

\subsubsection{Subject Game and Role Analysis}

Analyzing the roles of the four main bodies of waste sorting and recycling, it is found that the government has a certain contradiction when weighing the economic and ecological benefits involved in waste sorting. Residents, scavengers, and companies are not aware of their social role in garbage classification, and 
the division of roles is not clear. Through investigation and analysis, it is judged that the roles played by the attitudes of all parties in the garbage classification and recycling are utilitarian, open and expressive. As the main body that pays attention to actual benefits and the economic effects of behavior, the government assumes a utilitarian role. Recyclers can engage in activities based on their own understanding of the role and the society's expectations of the role, and become a socially open role without clear regulations. As a social role for the purpose of expressing social system and order, social behavior norms, values, etc., residents have become expressive roles. The three types of subjects have role conflicts in the garbage collection classification process due to their different attitudes (see Figure 6). When faced with the choice of recycling and sorting, different roles of residents and the government play a game in order to maximize their own interests. The game between different roles is also an important reason that makes it difficult to implement garbage classification.

\section{Establish a Tripartite Evolutionary Game Model for the Government to Supervise Waste Classification}

\subsection{Model Assumptions}

1) Game participants: government, private recyclers, residents.

2) The bounded rationality of game participants is to maximize their own interests as the goal.

3) Game rules: The game is first acted by residents, and the strategy set is (classification, no classification); then private recyclers act, and the strategy set is (private classification and recycling, no recycling); finally, the government department takes action, The strategy set is (supervised recycling, unsupervised recycling).

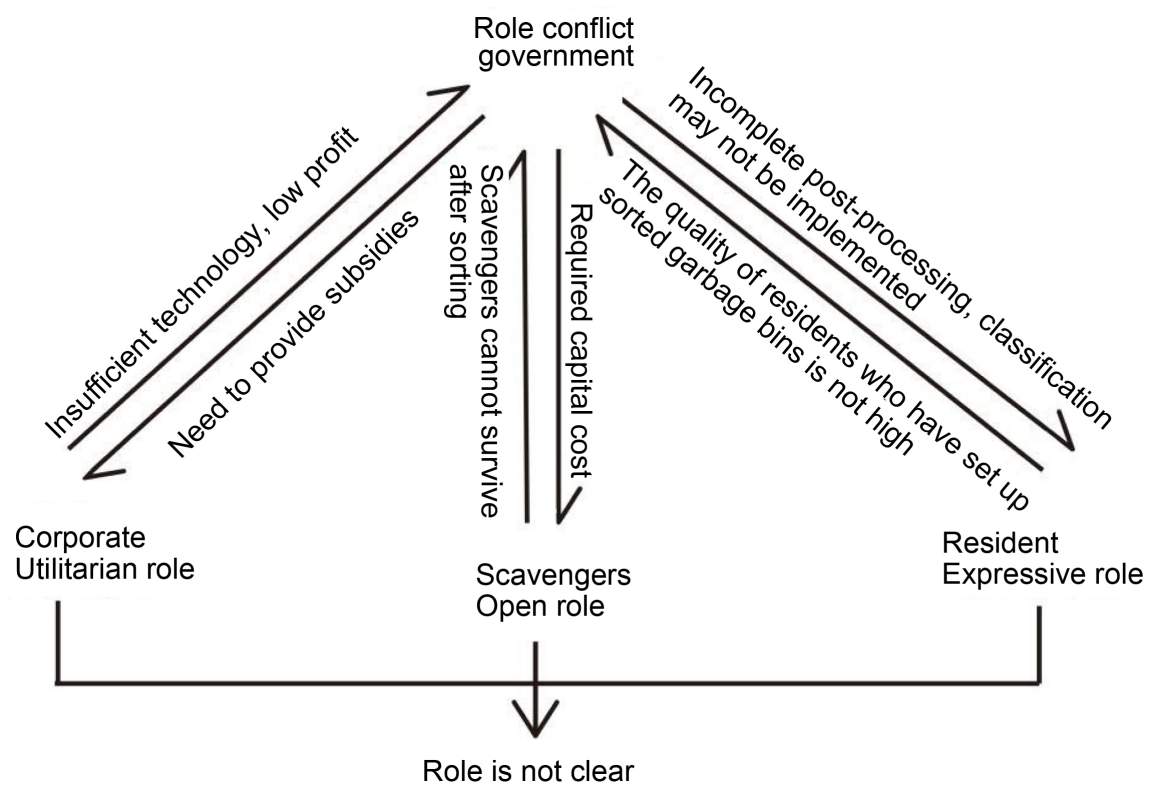

Figure 6. The attitudes of all parties to garbage collection. 
4) Parameters and variables. Among them, $R_{1}$ is the income obtained by community residents (such as ecological benefits after environmental improvement) after the garbage is classified and discarded according to the classification regulations by various entities; $R_{2}$ is the residents who do not classify the garbage according to the classification regulations and discard the garbage in violation of the regulations The extra benefit obtained from the behavior (the later stage is sorted by the unified sorting center; the sorting manpower and material resources are saved, etc.) is a function of the equivalent $\mathrm{x}$ of the illegally discharged garbage; $C_{1}$ is the value of the recyclable resources in the garbage discarded by the residents (here by default, the garbage is unified The classified and supervised community has no private recyclers to recycle), and is less than the revenue $R_{2} ; C_{2}$ is the cost of government supervision and manpower and material resources to build the sorting center due to non-classification; $F_{1}$ is the government supervision and discovery of unclassified behavior The penalty incurred later, we assume that it is greater than the personal income saved by residents in illegal discharge; $F_{2}$ is the fine when the government finds that private recyclers are illegally recycled; $E$ is the impact on the social environment caused by residents not classifying, We regard it as the profit and loss of the government department; $\alpha$ is the proportion of residents choosing classified investment, and the value range is $[0,1] ; \beta$ is the probability of private recyclers to classify privately, and the value range is $[0,1] ; \gamma$ is the probability that the government performs supervision, with a value range of $[0,1] ; U_{i}$ is the payment function of residents under different strategies; $V_{i}$ is the payment function of private recyclers in different combinations of strategies; $W_{i}$ is the government department's payment function in different strategies The payment function under the combination.

\subsection{Model Establishment}

Through the assumption of the model, a three-party game model of residents, private recyclers and government departments is established. The extended game model is shown (see Figure 7).

Based on the model assumptions and the extended three-party game tree, the payout function of the subject under different strategy combinations can be obtained (see Table 2).

In the model, another hypothesis is that if government agencies conduct supervision, they must be able to detect improper behaviors of residents and recyclers.

\subsection{Model Solving}

Through the three-way expansion game tree, you can see that there are 8 strategy combinations. Under the assumption of maximizing self-interest, the dynamic equation is used to copy the dynamic equation to solve the evolutionary stability strategy. Evolutionary stability strategy requires copying the function in 


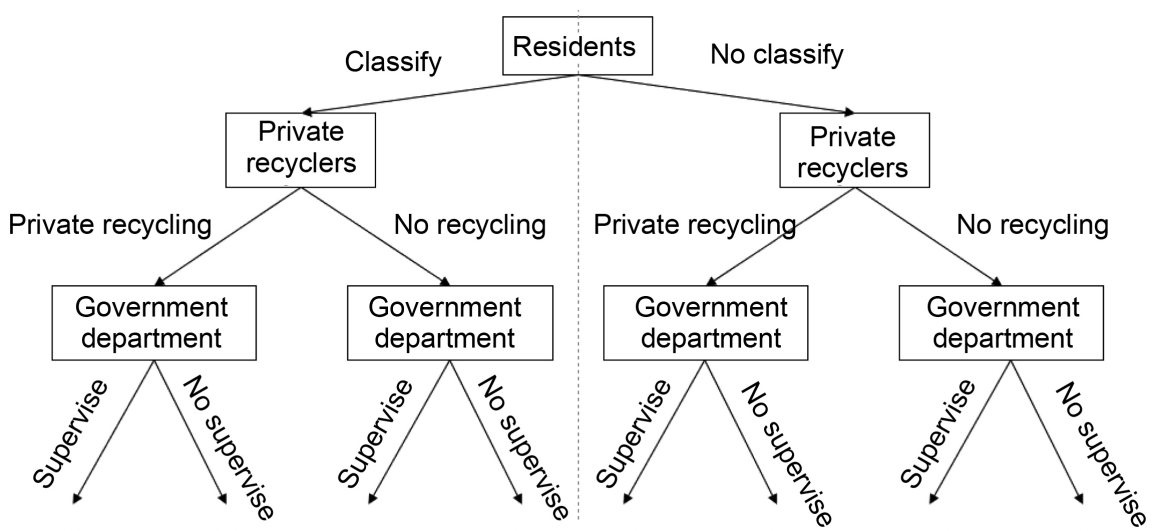

(1)

(3)

(4)

(5)

(6)

(7)

(8)

Figure 7. Three-party extended game model.

Table 2. Payout function of each game subject in the three-party game model.

\begin{tabular}{|c|c|c|c|}
\hline \multirow{2}{*}{$\begin{array}{l}\text { Strategy } \\
\text { portfolio }\end{array}$} & \multicolumn{3}{|c|}{ Payment function } \\
\hline & Residents & Private recyclers & Government department \\
\hline (1) & $U_{1}=R_{1}+R_{2}-C_{1}-F_{1}$ & $V_{1}=C_{1}-F_{2}$ & $W_{1}=F_{1}+F_{2}-C_{2}-E$ \\
\hline (2) & $U_{2}=R_{1}+R_{2}-C_{1}$ & $V_{2}=C_{1}$ & $W_{2}=-E$ \\
\hline (3) & $U_{3}=R_{1}$ & $V_{3}=0$ & $W_{3}=-C_{2}$ \\
\hline (4) & $U_{4}=R_{1}$ & $V_{4}=0$ & $W_{4}=0$ \\
\hline (5) & $U_{5}=R_{1}$ & $V_{5}=0$ & $W_{5}=-C_{2}$ \\
\hline (6) & $U_{6}=R_{1}$ & $V_{6}=0$ & $W_{6}=0$ \\
\hline (7) & $U_{7}=R_{1}+R_{2}-C_{1}-F_{1}$ & $V_{7}=0$ & $W_{7}=-C_{2}$ \\
\hline (8) & $U_{8}=R_{1}+R_{2}-C_{1}$ & $V_{8}=0$ & $W_{8}=0$ \\
\hline
\end{tabular}

the dynamic equation $G=0$ and $G^{\prime}<0$ [12].

1) Residents expect utility. The average expected utility of residents is

$$
U=\alpha\left[\beta\left(R_{2}-\gamma F_{1}-C_{1}\right)+R_{1}\right]+(1-\alpha) R_{1}=R_{1}+\beta \alpha\left(R_{2}-\gamma F_{1}-C_{1}\right)
$$

Then the resident's copy dynamic equation is

$$
\begin{aligned}
G(\alpha) & =\frac{d_{\alpha}}{d_{t}}=\alpha\left\{\left[R_{1}+\beta\left(R_{2}-C_{1}-F_{1} \gamma\right)\right]-\left[\alpha(1-\alpha) \beta\left(R_{2}-C_{1}-F_{1} \gamma\right)\right]\right\} \\
& =\alpha(1-\alpha)\left(R_{2}-C_{1}-F_{1} \gamma\right)
\end{aligned}
$$

Let $G(\alpha)=0$, we get, $\alpha=0$, or $\alpha=1$, or $\beta=0$

The cases of $\alpha=0$ and $\alpha=1$ are discussed below.

Among them, when $\alpha=1, G^{\prime}(1)=-\beta\left(R_{2}-C_{1}-F_{1} \gamma\right)$, when $\beta \neq 0$ and $R_{2}>C_{1}+F_{1} \gamma$, that is to say, the probability that private recyclers will choose to recycle privately is not zero. At the same time, residents who choose to discharge unsorted garbage outside the specified time and place will have an extra benefit greater than the recyclable garbage they can get from illegally discharged garbage. The value of plus the sum of the product of the probability of being supervised and enforced by the relevant government department and its fine. At this 
time, due to various reasons such as the lack of a complete supervision system for the garbage classification policy based on the community as the basic unit, the relevant supervision departments set up by the government currently have a low probability of performing supervision. In the evolution of the game, the residents' stable strategy is to choose Discharge of unclassified and illegal waste outside the time specified by the current management measures. Its irregular emissions will also stimulate private individual recyclers to conduct multiple illegal recycling.

Among then, when $\alpha=0, G^{\prime}(0)=\beta\left(R_{2}-C_{1}-F_{1} \gamma\right)$, when $\beta \neq 0$ and $R_{2}>C_{1}+F_{1} \gamma$, That is to say, the probability that private recyclers choose to conduct private recycling is not zero, and at the same time, residents who choose to discharge unsorted garbage outside the specified time and place will have an additional benefit less than the recyclable garbage they can obtain from illegally discharged garbage. The value plus the sum of the product of the probability of being supervised and enforced by the relevant government department and its fine. At this time, as the relevant government departments set up a reasonable law enforcement system to increase the probability of supervision and law enforcement, the extra income that residents get from illegal emissions is not enough to make up for related fines, etc. Therefore, the stable strategy of residents in the evolutionary game is not to conduct illegal emissions.

2) Private recyclers expect utility. The expected utility of private recyclers choosing to recycle privately and not to recycle are respectively

The average expected utility of the recycler is

$$
V=\alpha \gamma \times 0+\alpha(1-\gamma) \times 0+(1-\alpha) \times \gamma \times 0+(1-\alpha)(1-\gamma) \times 0
$$

Dynamic equation

$$
G(\beta)=\frac{d_{\beta}}{d_{t}}=\beta\left[\alpha\left(C_{1}-\gamma F_{2}\right)-\alpha \beta\left(C_{1}-\gamma F_{2}\right)\right]=\beta \alpha(1-\beta)\left(C_{1}-\gamma F_{2}\right)
$$

When $G(\beta)=0$, we get $\beta=0, \beta=1, \alpha=0, \gamma=C_{1} / F_{2}$, It can be clearly seen when $\alpha=0, \gamma=C_{1} / F_{2}, G^{\prime}(\beta)=0$, does not meet the requirements.

When $\beta=0, G^{\prime}(0)=\alpha\left(C_{1}-\gamma F_{2}\right)$, if $\alpha \neq 0$ and $C_{1}<\gamma F_{2}$, That is to say, when the probability of residents choosing to conduct unclassified illegal emissions at an unspecified time is greater than zero, and the income obtained by private recyclers through illegal recycling is less than the product of the probability of government supervision and the fines, private recyclers will choose not to Sort garbage for private recycling.

When $\beta=1, G^{\prime}(1)=-\alpha \gamma\left(C_{1}-\gamma F_{2}\right)$, if $\alpha \neq 0$ and $C_{1}>\gamma F_{2}$, we get $G^{\prime}(1)<0$. At this time, when residents choose to discharge unclassified garbage in violation of regulations, private recyclers gain more benefits by privately recycling unclassified garbage than the product of government supervision probability and fines. In order to maximize their own interests, they choose to Private recycling-style evolutionary stability strategy.

3) Government expectation effect. The expected utility of government agen- 
cies choosing to supervise or not to supervise are respectively

The average expected utility of the government is

$$
W_{1}=\alpha \beta \times 0+\alpha(1-\beta) \times 0+(1-\alpha) \beta(-E)+(1-\alpha)(1-\beta)(-E)=(\alpha-1) E
$$

Its copy dynamic equation is

$$
\begin{aligned}
W_{2}= & \alpha \beta\left(F_{2}-C_{2}-E\right)+\alpha(1-\beta) \times 0+(1-\alpha) \beta\left(F_{1}+F_{2}-C_{2}-E\right) \\
& +(1-\alpha)(1-\beta)\left(F_{1}+F_{2}-C_{2}-E\right) \\
= & \left(F_{1}+F_{2}-C_{2}-E\right)(1-\alpha)+\alpha \beta\left(F_{2}-C_{2}-E\right)
\end{aligned}
$$

When $G(\gamma)=0$, we can get $C_{2} /\left(F_{1}+F_{2}\right) \cdot C_{2} /\left(F_{1}+F_{2}\right), G^{\prime}(\gamma)$ always equal to zero, so $\alpha \beta=C_{2} /\left(F_{1}+F_{2}\right)$ not the evolutionary stable strategy of government departments in an evolutionary game.

When $\gamma=1, G^{\prime}(0)=-\alpha \beta\left(F_{1}+F_{2}\right)+C_{2}$, if $\gamma=1$ evolutionary stable strategy, get $C_{2}<\alpha \beta\left(F_{1}+F_{2}\right)$, That is, the supervision cost of the government department is less than the product of the probability that both private recyclers and residents choose to discharge garbage in violation of the rules and the sum of the fines received by the two entities at the same time. Then the best choice for the government department is supervision.

When $\gamma=0, G^{\prime}(0)=\alpha \beta\left(F_{1}+F_{2}\right)-C_{2}$, if $\gamma=0$ evolutionary stable strategy, get $C_{2}>\alpha \beta\left(F_{1}+F_{2}\right)$, That is to say, the supervision cost of government departments is greater than the product of the probability that both private recyclers and residents choose to discharge garbage in violation and the sum of fines, so the best choice for government departments is no supervision.

Through the analysis of the evolutionary stability strategies of residents and private recyclers, their equilibrium strategies are only related to the supervision probability of government departments, while the choice between these two types of subjects is less relevant. This is mainly because, to some extent, residents and private recyclers may have some interest in the residual value of the garbage, so they may choose to premeditate against government supervision. Whether the government chooses to supervise or not mainly depends on the predicted collusion probability $\alpha \beta$ between residents and private recyclers under the current circumstances and the fine $\left(F_{1}+F_{2}\right)$. if the two types of subjects are found to be colluding in their choices.

\subsection{Jacobi Matrix Verification}

From the analysis of the three-party evolutionary game copy dynamic equation, we can see that there are 8 strategies in the game process, namely $(1,1,1),(1,1$, $0),(1,0,1),(1,0,0),(0,1,1),(0,1,0),(0,0,1)(0,0,0)$. We use the dominant strategy to analyze it and find that after substituting specific values $(1,0,1),(1,0$, $0),(0,1,1),(0,0,1),(0,0,0)$ The 5 strategy combinations will cause the recyclable value of the remaining garbage and the supervision cost to be less than zero, which is contrary to the actual situation and is excluded. In addition, in the two cases where the government chooses to supervise and not supervise, the Jacobian matrix is used to analyze the local stability of the remaining evolutionary stabili- 
ty strategy combination. The judgment is mainly based on the similarities and differences between the value of the determinant and the sign of the matrix trace. Those with the same sign are unstable stagnation points, and the signs with different signs are evolutionary stability strategy signs that cannot be determined as saddle points. Based on the relationship between the variables in different strategies, the results of stability analysis using a matrix (see Table 3 ).

Based on matrix analysis, it can be concluded that the evolutionary stabilization strategies of residents and private recyclers are the same in both cases of government review and non-review. Relying on the relationship between government policies and the residual value of the garbage discharged, the government's fines for residents who discharge illegally and private recyclers, and the additional benefits that residents obtain after choosing illegal discharge, the evolutionary stability strategy may be (emissions, Private recycling, supervision) and (discharge, private recycling, no supervision).

\subsection{Model Analysis}

\subsubsection{Influencing Factors of Private Recyclers Strategy}

Private recyclers choose to recycle in violation of regulations will generate additional economic benefits, but also bear the risk of government supervision. The model assumes that the recyclers are rational, and the ultimate goal is to maximize their own interests. By copying the dynamic equation, it can be found that the factors that affect the reclaimer's strategy are the extra income of choosing to reclaim privately, and the probability of government supervision, that is, the fine. Through the research on the probability of government supervision, the recyclers will compare the extra income $R_{2}$ with the size of $\gamma F_{1}+C_{1}$ according to their own situation, and then choose a stable strategy.

Before the city entered the stage of compulsory garbage classification, as an important group of private recyclers, more than 30,000 people participated in the collection of waste in the community. Although the unsorted garbage was roughly "naturally classified", in reality, because of waste collection When people pick up the garbage, they scatter the garbage on the ground, which causes the surrounding air to be polluted, which has a negative impact on the image of the environment. At the same time, the disorder and unorganized nature of scavengers themselves, the possibility of potential group crimes, will also bring certain

Table 3. Stability analysis of Jacobian matrix.

\begin{tabular}{ccccccc}
\hline & $\begin{array}{c}\text { Strategy } \\
\text { portfolio }\end{array}$ & $\operatorname{Det}(\mathrm{J})$ & symbol & $\operatorname{Tr}(\mathrm{J})$ & symbol & stability \\
\hline $\begin{array}{c}\text { Government } \\
\text { review }\end{array}$ & $(1,1,1)$ & $\begin{array}{c}R_{2}-F_{1}-C_{1} \\
C_{1}-F_{2}\end{array}$ & + & $F_{1}+F_{2}-R_{2}$ & - & ESS \\
\hline $\begin{array}{c}\text { The government } \\
\text { does not review }\end{array}$ & $(1,1,0)$ & $C_{1}\left(R_{2}-C_{1}\right)$ & + & $-R_{2}$ & - & ESS \\
\hline & 0 & indefinite & $R_{2}-F_{1}-C_{1}$ & - & $\begin{array}{c}\text { Saddle } \\
\text { point }\end{array}$ \\
\hline
\end{tabular}


damage to the city's safety facilities, and their role is embarrassingly positioned in the government management system. Since the implementation of the management method, the contradiction between garbage classification and scavengers has become more prominent. Due to the implementation of garbage classification, all the trash bins at the entrance of the community have been collected, and a designated garbage dumping station has been set up. The garbage collection is fixed at two hours in the morning and evening every day. The garbage collection time is fixed. In the past, the property will also lock or tow the trash cans, so that scavengers cannot easily approach them for recycling. Under such circumstances, the government's supervision of scavengers and increased penalties for private recycling will effectively curb the phenomenon of private recycling. However, scavengers who give up scavenging will lose their source of livelihood. If there is no proper treatment plan, it will be inevitable. This will increase the conflict of interest between this group and the government.

\subsubsection{Influencing Factors of Residents' Strategy}

In the game model, the residents' main income comes from the extra income brought by the manpower and material resources saved when the classification is not carried out, and part of the income obtained by providing specific garbage to the recyclers. If you choose to discharge illegally, residents will not only bear the risk of government supervision, but also consider the impact of reputation among neighbors if they are reviewed. After residents compare the extra income with the probability of government supervision and fines, if the extra income is not enough to make up for the possible penalty loss caused by government supervision, then the residents will choose to classify to maintain their own interests.

According to Article 49 of the "Measures for the Classification and Management of Domestic Waste in Xi'an City", if a unit or individual throws domestic waste at will in violation of the regulations, the individual will be fined more than 100 and less than 200, and the unit will be fined more than 5000 and less than 20,000, and bad information will be included in the personal collection. Letter system. On September 3, the Urban Management and Comprehensive Law Enforcement Bureau of Yanta District, Xi'an City issued the first administrative penalty decision since Xi'an implemented garbage classification: a residential property company was fined 1000 yuan, and for several days, the relevant departments respectively dealt with the districts. The internal garbage transportation fleet fails to classify and transport domestic garbage, the body of garbage transportation vehicles is unclean, and the garbage collection enterprise fails to collect the garbage according to the requirements and issues fines, each with fines ranging from 2000 to 10,000 yuan. At present, there are no fines issued against individual residents. The community's garbage classification is guided and supervised by the property company setting up supervisors, using regular and fixed-point discharge, and supervisors patrolling. However, this has increased the burden on residents and caused neighbourhoods. On the other hand, 
the rebellious sentiment between the property companies has invested a lot of manpower and material resources, and faces government penalties, which makes many communities hold the attitude of "unclassified without being discovered", making garbage classification difficult.

\subsubsection{Influencing Factors of Government Strategy}

Compared with residents and private recyclers, government departments, in addition to economic interests, will increase their own interests by maintaining the ecological environment. The cost of government supervision is generally relatively fixed. If residents and private recyclers choose to collude, government supervision can make up for economic losses with fines; if the government does not supervise, in addition to economic losses, environmental benefits will also be lost. Therefore, whether the government supervises or not, the cost of supervision should be compared with the sum of fines, and the economic and environmental benefits should be considered comprehensively.

The government has invested a lot of resources in the implementation of waste classification in Xi'an. While increasing various terminal treatment facilities, it has also strengthened the classification of community residents and conducted a lot of publicity and education. However, because the current supervision agencies and corresponding penalties are unreasonable, The interests of various groups cannot be balanced in the existing mechanism, and the government is in a situation where there is more than enough energy to sort out the entire garbage.

\section{Mechanism Countermeasures and Suggestions}

\subsection{Recycler's Perspective}

After the management regulations are implemented, the garbage will be processed by the enterprise, and the recyclers will face unemployment. In order to solve the problem of the survival of the recyclers, as well as the situation that the specific supervision and classification executive body has not yet clearly stipulated the situation in the classification and supervision of the current implementation of the management regulations, the role of the recyclers is changed, that is, the role of the recyclers is changed. Garbage for a living becomes the executor of the community's supervision of the residents' garbage sorting and disposal, and the property department pays wages. This way, on the one hand, the life of the scavengers is guaranteed and the living environment of the scavengers is improved, and on the other hand, it can make up for the current lack of supervision status.

The existence of waste recycling stations is not conducive to the disposal of recyclable items by relevant enterprises through a unified and formal channel. That is to say, due to the existence of interests, the scavengers who have changed their roles will still sell recyclable items to private recycling stations. Therefore, the role of private waste recycling stations should be promoted as soon as possible. The waste recycling stations can be used as a concentration point for companies to collect recyclable items, and become the final sorting point before the 
end of the household garbage and the separation point for large-sized garbage in the city. The disposal is harmful. Enterprises dealing with garbage, recyclable items and large items shall actively introduce advanced treatment technologies to improve the capacity of garbage treatment and utilization.

\subsection{Residents' Perspective}

Residents are the most important subject of waste sorting and recycling, that is, if residents sort from the source, they will avoid the need for a large amount of human, material and financial resources for re-sorting. Residents classify and put in trash cans every day, throw different types of trash into corresponding trash cans in the community, and accept inspection or punishment by supervisors. At the same time, residents can also act as facilitators of supervision and classification. The elderly in the community can directly participate in the supervision of garbage classification in the community, which can not only enrich the leisure life of the elderly but also promote the interaction between neighbors.

\subsection{Government Perspective}

The government plays an important role in the garbage sorting and recycling process, such as coordinating the hardware configuration and personnel placement of garbage disposal and providing financial support. The treatment process and technical indicators of landfills, composting plants, especially incineration plants should be open and transparent. Appropriate compensation shall be provided to residents affected by the establishment of garbage disposal sites. Provide financial support for enterprises dealing with hazardous waste, recyclable waste, and large items, and create a good market environment for such enterprises.

The government supervision and punishment system is an important factor in the selection of strategies for residents and recyclers. A complete supervision and punishment system can reduce the probability of collusion, so that the government can restrict the behavior of residents and recyclers. The government can directly increase the cost of violations by residents and recyclers by setting up a multi-level supervision system and increasing penalties, so that the additional economic benefits after violations are not enough to make up for the loss of violations. In addition, the supervision system can also be expanded and improved by implementing a supervision responsibility system for the person in charge of community classification.

\section{Conflicts of Interest}

The authors declare no conflicts of interest regarding the publication of this paper.

\section{References}

[1] Zhang, Y.M., Shang, X.B., Li, K.M., Zhang, C.S., Zhang, K.F. and Rong, H.W. (2011) Status Quo of Municipal Solid Waste Treatment Technology and Management Countermeasures. Journal of Ecological Environment, 20, 389-396. 
[2] Wu, Y.P. and Dong, S.C. (2001) Current Status and Prospects of Contemporary Urban Domestic Waste Disposal Technology-Concurrently Discussing the Adjustment of the Perspective of China's Urban Domestic Waste Countermeasures. Urban Environment and Urban Ecology, 1, 15-17.

[3] Song, X.L. (2001) Urban Waste Treatment and Sustainable Development. Journal of Changsha University, 4, 36-40.

[4] Tan, W.Z. (2011) Urban Domestic Waste Dilemma and Institutional Innovation: Taking Taipei Municipal Domestic Waste Classification and Management as an Example. Urban Development Research, 18, 95-101.

[5] Yang, Z.J. (2003) The Impact of Construction Waste on the Urban Environment and Its Solutions. Urban Issues, 4, 60-63.

[6] Lu, Y.F. and Sun, X.J. (2002) Discussion on the Countermeasures for the Classification and Collection of China's Urban Domestic Waste. Environmental Sanitation Engineering, 1, 15-17+32.

[7] Lv, J.Y. and Yang, H. (2019) Research on the Government's Tripartite Evolutionary Game of Carbon Market Supervision-Based on the Perspective of Rawlsian Social Welfare Function. Coal Economic Research, 39, 77-82.

[8] Liu, S.B. (2019) Research on the Treatment of Urban Domestic Waste in Xi'an. Chang'an University, Xi'an.

[9] Kong, Y.R. (2018) Research on Guangzhou Municipal Solid Waste Governance Based on Big Data. South China University of Technology, Guangzhou.

[10] Zhou, L.J. (2013) Research on the Countermeasures for the Waste Problem in my country's Small Cities-A Discussion on Government Responsibilities and Urban Waste Management System. Modern City Research, 28, 40-43.

[11] Liu, Z. and Zhang, H.Y. (2017) Investigation on the Awareness of Household Garbage Classification in Xi'an. Environmental Sanitation Engineering, 25, 14-16.

[12] Chen, F.J. and Huang, J.L. (2015) Research on the Evolution of Network Public Opinion from the Perspective of Tripartite Game. Information Science, 33, 22-26. 